\title{
SYSTEM FOR MEASUREMENT OF TEMPERATURE OF BIOLOGICAL TISSUES IN BIPOLAR HIGH-FREQUENCY WELDING
}

\author{
Yu.N. LANKIN, L.F. SUSHY and E.N. BAJSHTRUK \\ E.O. Paton Electric Welding Institute, NASU \\ 11 Bozhenko Str., 03680, Kiev, Ukraine. E-mail: office@paton.kiev.ua
}

\begin{abstract}
HF welding of soft biological tissues using bipolar electrosurgical instrument is basically similar to resistance spot welding of metals. Physical-biological processes, taking place in tissues during welding, mainly arise from their heating and applied pressure. Thus, information about temperature in contact of tissues during welding is very important. There are virtually no publications on equipment and measuring of temperature in welding of biological tissues. Standard thermocouples with wires of small diameter $(70 \mu \mathrm{m})$, as the tiniest, were used as temperature probes. Heat generation of thermocouple due to welding current passing through it is virtually absent in comparison with heat generation in tissue. Distortion of electric and temperature fields in the vicinity of thermocouple can be neglected. Thermal time constant of chosen thermocouple makes around $8 \mathrm{~ms}$ based on reference data. Measurement system consists of chromel-alumel thermocouple with wire of $70 \mu \mathrm{m}$ diameter, themoEMF amplifier, analog filer of lower frequencies, ADC and laptop. The experiments show that thermocouple can be represented by pure first-order time delay. Thermal time constant of thermocouple is $4.3 \mathrm{~ms}$, time delay makes around $1 \mathrm{~ms}$. Analog filter of lower frequencies completely suppresses welding current noises and determines general band of temperature measurement system of $25 \mathrm{~Hz}$ width. Developed system allows for measuring the temperature in contact of biological tissues during HF welding using bipolar electrosurgical instrument without dynamic errors and provides no distortions in tissue temperature field. 9 Ref., 6 Figures.
\end{abstract}

$\boldsymbol{K} \boldsymbol{e} \boldsymbol{y} \boldsymbol{w} \boldsymbol{O} \boldsymbol{d} \boldsymbol{s}:$ welding of biological tissues, measurement of temperature, thermocouple, thermal time constant, filtering of welding current noises

Basically, bipolar HF welding of biological tissues is completely similar to resistance spot welding. Two parts of the tissue are compressed by two electrodes with some force and further heated by current passing through the tissue. Tissue significantly changes as a result of mutual effect of heat and applied pressure. It is denaturated, completely destructed and represents itself homogeneous mass of collagen, elastin and ground substances of tissues with significantly reduced boundaries between them, forming welded joint of two initially separated areas of tissue. Thus, heating of the tissues is a determining factor in HF welding of biological tissues. Therefore, it is important to know tissue temperature in welded joint being formed in study of all welding aspects. However, difficulties of measurement of temperature of joint during welding resulted in insufficient study of this problem.

We have found only one publication [1] providing experimental curves of change of temperature of albumin and wall of artery during heating by HF electric current using bipolar surgical instrument (Figure 1). Curves in this Figure

(c) Yu.N. LANKIN, L.F. SUSHY and E.N. BAJSHTRUK, 2014 are obviously significantly retouched and given only for illustration of dependencies of curve trend.

Several oscillograms of change of temperature of tissue in contact during welding (Figure 2) are also shown in the first PWI report on welding of biological tissues [2]. Unfortunately, the report does not provide for a procedure of temperature measurement. It was only indicted that the temperature was measured in «zone of welding».

Further the measurements of temperature were only carried out on the surface of tissue being welded in the electrode vicinity with the help of pyrometer. Experience of resistance spot welding of metals does not suppose sufficiently high correlation of this temperature with weld nugget parameters. Integral temperature of tissue surface in the electrode vicinity describes a width of HAZ and to significantly lesser degree welded joint itself. It should be noted that the HAZ width has a decisive impact on further angenesis in the welded joint.

There are several patents [3-7] on welding instrument using measurement of electrode temperature by thermocouples for control and automatic regulation of welding process. This method, the same as for resistance spot welding of metals, did not find practical application due 
to complexity and unreliability of instrument and, principally, because of low correlation of temperature of electrode contact surface with temperature of contact in welding.

Temperature probe. Thickness of tissue in welded joint can be less than millimeter, that results in necessity of application of tiny temperature probes. The optimum solution is application of small diameter thermocouples. The industry produces thermocouples with wire diameter up to $4.5 \mu \mathrm{m}$ [8]. Diameter of seam bead of such a thermocouple equals approximately three diameters of its wires, i.e. $15 \mu \mathrm{m}$. Widespread thermocouples of $J$-(iron-constantan) or $K$-type (chromel-alumel) suit well for $40-200{ }^{\circ} \mathrm{C}$ temperature range appearing in welding of biological tissues. Thermocouples of $K$-type of $70 \mu \mathrm{m} \mathrm{di-}$ ameter $\left(0.0031^{\prime \prime}\right)$ were taken.

Welding of biological tissues is carried out using overlapping or along the flanged edges. The thermocouples are placed between the tissues to be welded along the electrode axis. As a result, part of welding current passes through it. Let's estimate heating of thermocouple by current passing through it. The heat, emitting in the thermocouple, is proportional to specific resistance of thermocouple material $\rho$. Specific resistances of wire material of used $K$-type thermocouple (chromel and alumel) equal 0.66 and $0.33 \mu \mathrm{Ohm} \cdot \mathrm{m}$, respectively. Specific resistance of the most electro-conductive substance of human body - blood plasma - is $0.66 \mathrm{Ohm} \cdot \mathrm{m}$, i.e. 6 orders higher of specific resistance of thermocouple material. Therefore, welding current, passing

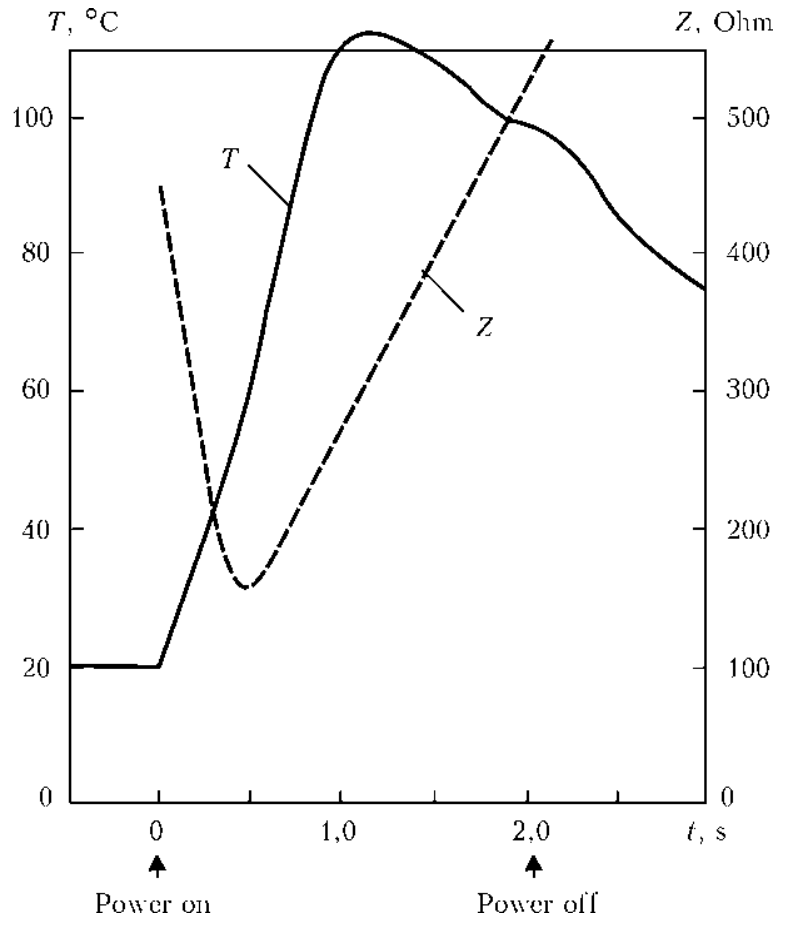

Figure 1. Change of temperature $T$ and impendence $Z$ of artery in heating by HF current [1]

through thermocouple seam, can not provide for additional heating and, thus, distort measurement results.

High electric conductivity of thermocouple material provides for distortion of electric field in the vicinity of seam to be measured. Let's represent thermocouple in form of cylinder. Field density on the surface in external electrostatic field for conductive cylinder of relatively small diameter is proportional to cosine of angle between field density vector and corresponding ra-

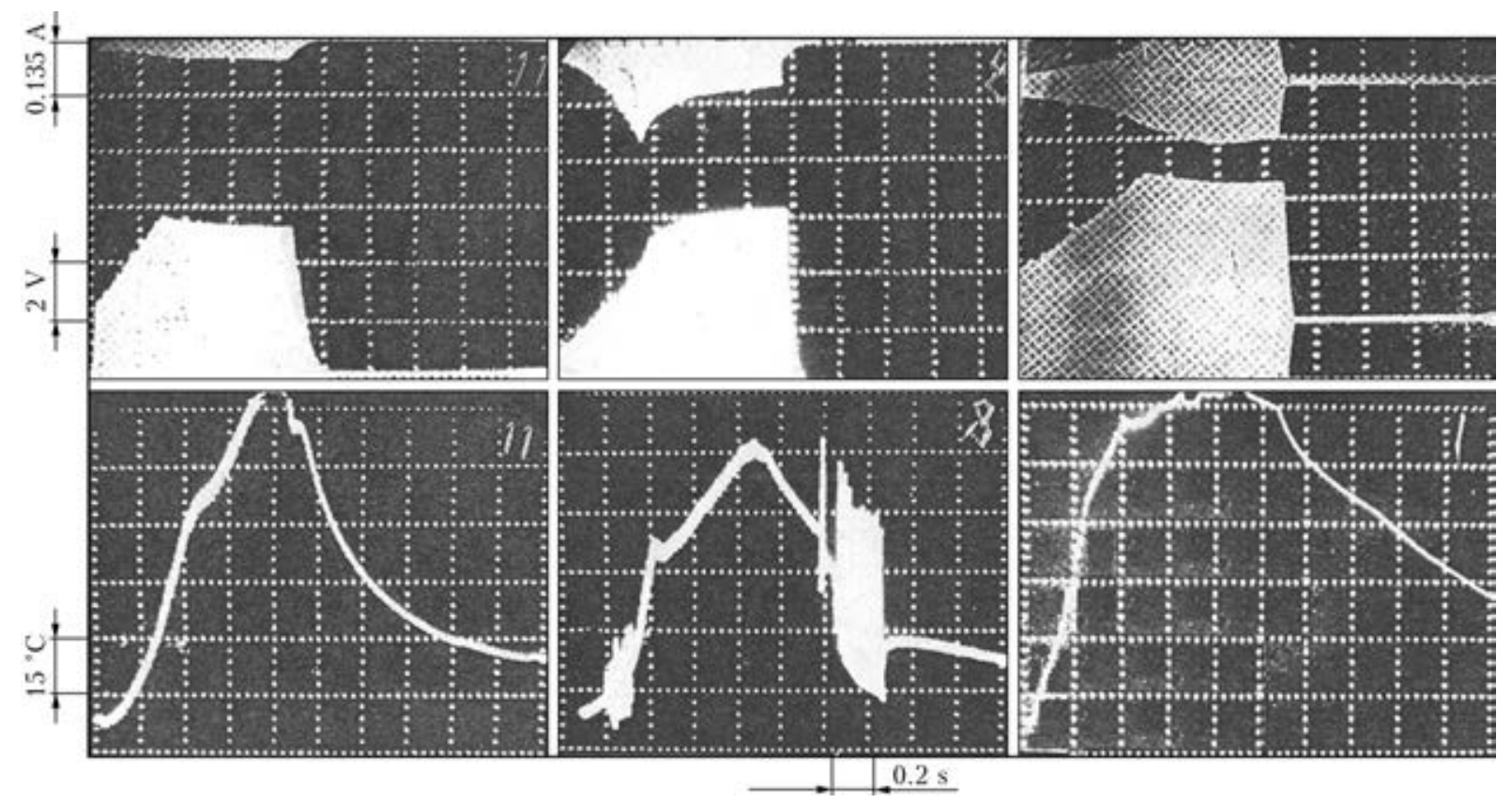

Figure 2. Oscillograms of welding current and voltage, temperature of contact in welding during variation of mode parameters [2] 


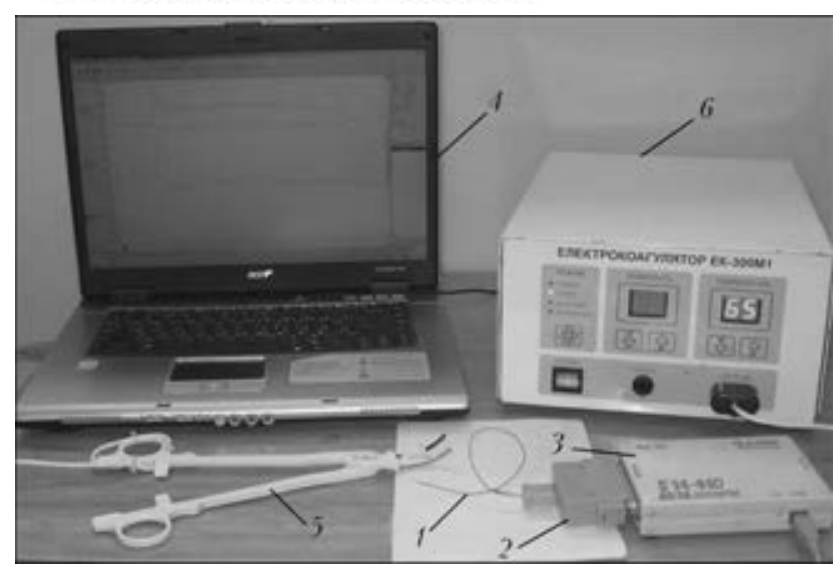

Figure 3. General view of system for temperature measurement in bipolar HF welding of soft biological tissues (for designations see the text)

dius-vector of cylinder [9]. Current density and emitting heat are respectively changed in this area. However, average heat emission on cylinder surface shows small variation and makes only 0.785 part of undisturbed electrostatic field. Since heat conduction of thermocouple material is around $90 \mathrm{~W} /(\mathrm{m} \cdot \mathrm{K})$ and that of water, determining heat conduction of biological tissues, makes approximately $0.68 \mathrm{~W} /(\mathrm{m} \cdot \mathrm{K})$, i.e. two orders lower, then the thermocouple temperature in the whole volume is similar and provides for alignment of nonuniformity of temperature in tissue adjacent to the thermocouple. Thus, effect of comparatively small thermocouple on temperature of tissues in welding can be neglected in first approximation.

Dynamic error of thermocouple depends on diameter of its wire. Experimental thermal time constant of iron-constantan thermocouple with wire diameter $0.005^{\prime \prime}$, measured at holding in still water with 93 and $38{ }^{\circ} \mathrm{C}$ temperature, equals $0.04 \mathrm{~s}$ [8]. Heating time constant, based on theory of similarity, is proportional to square of diameter of thermocouple wire. Respectively, time constant equals $0.015 \mathrm{~s}$ for thermocouple of $0.0031^{\prime \prime}$.
Data of $J$-type thermocouple is extrapolated to $K$-type thermocouple. According to homochronous criterion, time constant is inversely proportional to coefficient of thermal conductivity of material. $1.119 \cdot 10^{-5} \mathrm{~m}^{2} / \mathrm{s}$ was taken as average for iron $\left(1.626 \cdot 10^{-5} \mathrm{~m}^{2} / \mathrm{s}\right)$ and constantan $\left(0.612 \cdot 10^{-5} \mathrm{~m}^{2} / \mathrm{s}\right)$. Material of $K$-type thermocouple consists from nickel by $90 \%$. Coefficient of thermal conductivity of nickel is $2.29 \cdot 10^{-5} \mathrm{~m}^{2} / \mathrm{s}$. Thus, it can be supposed that time constant of used chromel-alumel thermocouple will be 2 times lower than that of $J$-type thermocouple, i.e. around $8 \mathrm{~ms}$.

System for temperature measurement. Figure 3 shows an experimental system of measurement of temperature in welding of biological tissues. The system consists of thermocouple 1 , amplifier of thermoEMF 2, external ADC modulus E14-440 «L-Card» 3, laptop with PowerGraph software 4. Bipolar electrosurgical forceps 5 and HF electrocoagulator EK-300M1 6 (serially manufactured by International Association «Welding») were used in measurements.

ThermoEMF amplifier was produced based on specialized microscheme AD592 Analog Device (Figure 4). Microscheme transforms thermoEDF of thermocouple into normalized voltage with conversion coefficient $10 \mathrm{mV} /{ }^{\circ} \mathrm{C}$. Microscheme realizes imbedded compensation of cold seam and linearization of transfer characteristic for $K$-type thermocouple, that guarantees measurement accuracy of $1{ }^{\circ} \mathrm{C}$ in all range of measured temperatures.

Receiving $C 1, R 1, R 2, C 2$ and output $R 3$ and $C 3$ filters of lower frequencies were used for hardware filtering of noises of mains voltage and welding source.

The main noises in temperature measurement channel appear in passing of current through tissue being welded (Figure $5, a$ ). It can be seen from Figure that level of noises in the output temperature signal is sufficiently high at absence

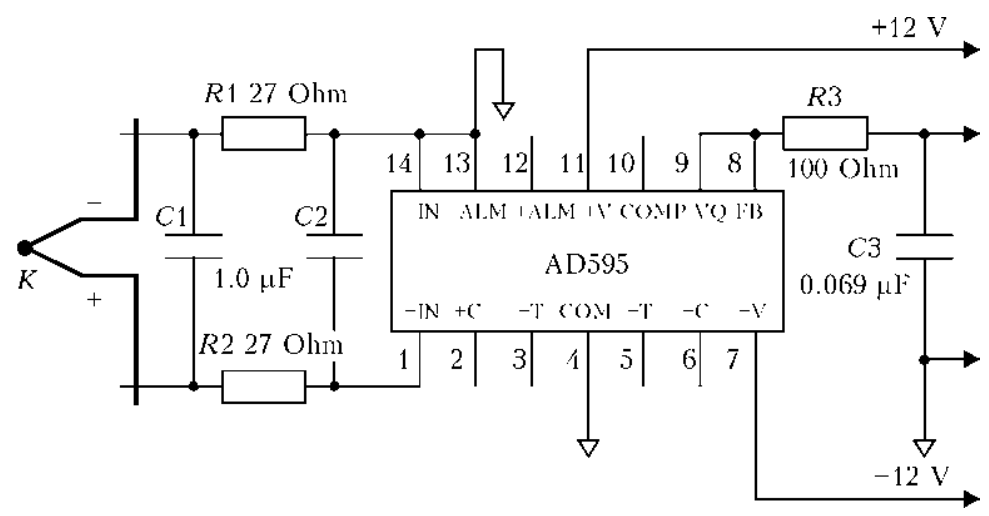

Figure 4. Schematic circuit of thermoEMF amplifier of chromel-alumel thermocouple 


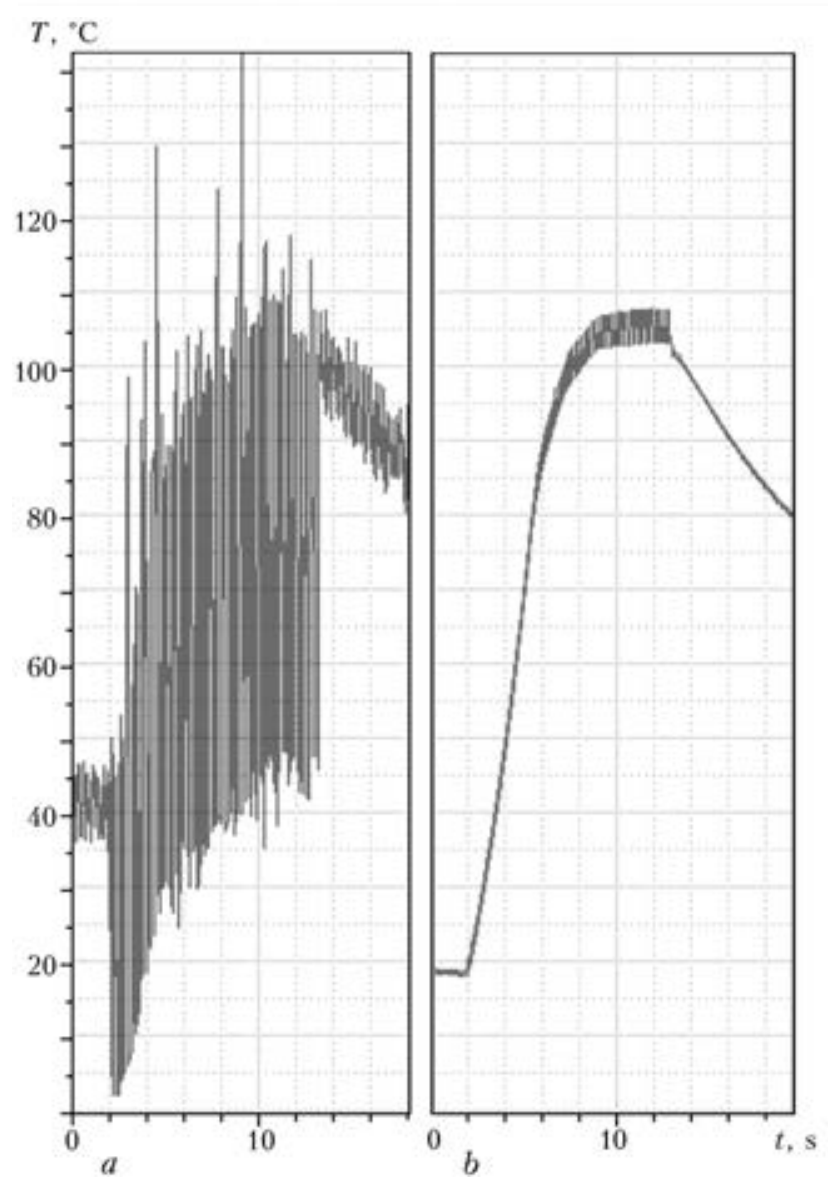

Figure 5. Registration of temperature in welding of pig intestine: $a-$ without filtering; $b-$ in presence of hardware filters of lower frequency acc. to Figure 4

of filtration. Applied multisection filter promotes almost complete elimination of noises and, at the same time, provides for acceptable pass band of measurement system $25 \mathrm{~Hz}$.

The following experiments were carried out for estimation of response time of thermocouple with nomination amplifier. Specially designed device of spring-release machine type was used for quick positioning of thermocouple in hot water and fixing of curve of its temperature change, namely transient-response curve. Noise filters were removed from amplifier scheme (see Figure 4) for measurement of only thermal time constant of thermocouple. Figure 6 shows one of received transient-response curves. It looks like heating curves typical for real physical bodies, and is usually described by exponent with time constant $T$ and time of pure delay $\tau . T=4.3 \mathrm{~ms}$ and $\tau=1.2 \mathrm{~ms}$ were found from Figure 6 . In fact $\tau$ value is somewhat lower, since it included time of thermocouple heating by vapors during its movement to water surface.

It is supposed that thermo-physical properties of biological tissues to be welded are close to

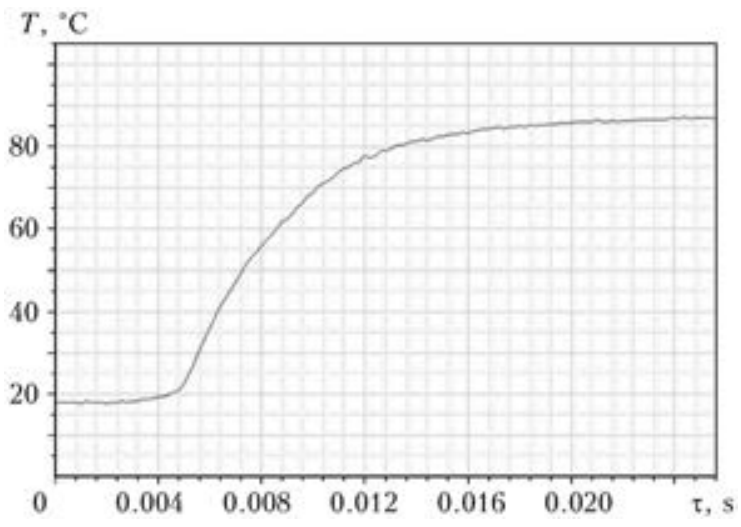

Figure 6. Curve of heating of thermocouple in water

properties of water. Coefficient of thermal conductivity of water in $40-90{ }^{\circ} \mathrm{C}$ range equals approximately $16 \cdot 10^{-8} \mathrm{~m}^{2} / \mathrm{s}$, that 2 orders lower than the coefficient of thermal conductivity of thermocouple material. Consequently, thermal time constant of the biological tissue is 100 times higher than thermocouple time constant. Therefore, it can be assumed that response time of the thermocouple do not provide for significant dynamic disturbances in measurement of temperature during welding of biological tissues even at welding current modulation. The main response time of temperature measurement system in our case is determined by pass band of electrical noise filter from welding current passing in area of hot thermocouple seam, and noises of supply mains.

It should be noted in the conclusion that the developed system allows measuring the real temperature of contact of biological tissues in HF welding using bipolar electrosurgical instrument without dynamic errors and significant disturbances in tissue temperature field.

1. Bergdahl, B., Vallfors, B. (1991) Studies on coagulation and development of an automatic computerized bipolar coagulator. J. Neurosurg., 75(8), 148-151.

2. (1994) Development of methods for welding of blood vessels: Report UA 01009046 R. Kiev: PWI.

3. Ensslin, F.H. Bipolar electrosurgical forseps. Pat. 4,938,761 US. Publ. 07.1990.

4. Klisek, M.S. Impedance and temperature generator for control. Pat. 5,496,312 US. Publ. 03. 1996.

5. Strub, B., Alto, P. Method and system for radiofrequency ablation of tissue. Pat. 5,540,681 US. Publ. 07.1996 .

6. Hassler, W.L. Method and apparatus for electrosurgically treating tissue. Pat. 5,540,684 US. Publ. 07.1996.

7. Baker, J.A. Method and apparatus for welding blood vessels. Pat. 6,083,223 US. Publ. 07.2000.

8. (1992) Omega: Complete temperature measurement handbook and encyclopedia. Engineering INC, Vol. 28.

9. Govorkov, V.A. (1968) Electric and magnetic fields. Moscow: Energiya.

Received 30.04.2014 